\title{
Consideraciones en torno a la cuestión étnica en Atacama
}

Francisco JaVier Rivera F.'

\section{RESUMEN}

Este artículo examina los problemas y las bases teóricas que se han aplicado en Atacama para estudiar la cuestión étnica regional, y propone algunos temas de investigación en la región, de acuerdo con desarrollos recientes en el debate sobre los estudios étnicos.

\section{ABSTRACT}

This paper examines the theoretical basis and problems to be applied in Atacama for the study of the region's ethnic question, and proposes some topics for the region's research, in accordance with recent developments in the ethnic studies's debate.

Al leer el detallado libro documental de Sergio Carrasco (1990), sobre la historia de las relaciones chileno-bolivianas, van apareciendo un cúmulo de temas que han marcado la agenda bilateral, con todos los encuentros y desencuentros diplomáticos que han estado presentes a lo largo de la historia republicana de ambas naciones hermanas. En fin, se ha negociado acerca de casi todo a lo largo de un poco menos de dos siglos. Se ha discutido sobre la delimitación fronteriza, las reparaciones de guerra, el curso de los cauces de los ríos, el tránsito de mercancías, la continuidad territorial, la salida al océano Pacífico, y muchos temas más. Pero en esta más que centenaria controversia prácticamente nadie se ha acordado de

1 Instituto de Investigaciones Arqueológicas y Museo "R.P. Gustavo Le Paige S.J." San Pedro de Atacama, Universidad Católica del Norte, museospa@entelchile.net los pueblos indígenas, habitantes originarios de estas tierras litigadas. Muy poco de los aymara, y nada de los atacameños. Es decir, podemos plantear con cierta seguridad que para los gobiernos bolivianos y chilenos a lo largo de la historia, más que no tomarlos en cuenta, simplemente no existía una clara conciencia de que estas comunidades tenían algo diferente, una identidad étnica, que desde la perspectiva estatal pudiesen significar diacríticos culturales que los distinguían del resto de los conciudadanos de sus respectivos países.

En el caso de los atacameños, el hecho de que sus rasgos culturales no hayan sido tomados en cuenta por el sentido común del chileno medio y de las autoridades del país, hasta los trabajos arqueológicos de Gustave Le Paige, y la consolidación del turismo en los últimos años, sólo por nombrar algunos hitos destacados, ha significado una falta de ensamblaje, de afiatamiento entre los datos socioculturales y los desarrollos teóricometodológicos de las investigaciones en la región, así como también que los giros argumentativos del discurso oficial, sobre la política y la administración que involucra a este pueblo indígena, cada cierto tiempo da giros inesperados, como ha sido el caso del sistema educativo, la tenencia de tierras y el patrimonio cultural, entre otros. Con la contraparte del masivo arribo de afuerinos, una inflación galopante de los insumos básicos, al grado de superar en un $1000 \%$ a la media nacional en la última década, tenemos una situación compleja y en algunos casos dramática, que por la amplitud de su cobertura, estamos obligados a dedicarnos en este trabajo a un tema específico: los problemas teórico-metodológicos que la investigación en ciencias sociales ha enfrentado en atacama, analizados a la luz de desarrollos teóricos recien- 
tes que se han generado en torno al debate contemporáneo sobre la cuestión étnica.

En los últimos veinte años se ha producido una verdadera explosión de estudios sobre la cuestión étnica, sobre todo en disciplinas que sólo se mantenían parcialmente conectadas con la antropología, como la ciencia política, la economía, el derecho, la filosofía, entre otras. Esto además del aumento considerable de los trabajos en las disciplinas que tradicionalmente se han dedicado a estudiar el tema, además de la antropología, como la sociología y la linguiística. Lo que ha generado una cantidad impresionante de trabajos, que abordan el tema étnico desde puntos de vista heterogéneos, con resultados también diversos; frente a lo cual nos encontramos ante la necesidad de perfilar nuestro sustrato teórico a las necesidades directas de nuestro objeto de estudio en atacama. En dichos términos, es menester realizar ciertas definiciones operacionales de conceptos, categorías y herramientas analíticas.

La identidad ha sido un área de interés para diversas vertientes teórico-analíticas de las cuales se destacan, la antropología de cultura y personalidad con Ralph Linton, Abram Kardiner, Cora DuBois, entre otros; el interaccionismo simbólico (George Herbert Mead, Herbert Blumer, Erving Goffman entre otros), la fenomenología social (Alfred Schutz, Peter Berger, Thomas Luckmann), la escuela francesa de las representaciones colectivas (en su origen Emile Durkheim y Maurice Halbawchs y ahora Serge Moscovici en psicología social), los teóricos de los movimientos sociales (Alain Touraine, Alberto Melucci, Charles Tilly, Sydney Tarrow, etc.), los post gramscianos (Alberto Cirese, Lombardi Satriani), y por supuesto, la inmensa mayoría de los investigadores que trabajan en la cuestión étnica.

Si bien sigo concordando con lo planteado originalmente en un trabajo anterior (Rivera, 1998), es necesario profundizar algunos conceptos, en los cuales yo hice una crítica a una suerte de esencialismo culturalista presente en la gran mayoria de los trabajos realizados en torno a la etnia atacameña.

La identidad en sus diversas adjetivaciones, particularmente la identidad étnica, tiene muchas facetas, al igual que su concepto derivado de etnicidad pero, existe un eje fundamental, el cual es menester mantener presente. En el caso de la etnicidad este es particularmente evidente. Siguiendo a Adams (1995b:72-73), existiría una suerte de identidad de definición dual, una identidad interna y una identificación externa; la autoorganización interna de los contenidos culturales de una etnia, es definitivamente diferente a la percepción externa que otras etnias tienen o pueden tener sobre la etnia en cuestión. No es escaso encontrar casos de apresuradas homologaciones arbitrarias entre lo que unos piensan de si mismos, y lo que otros estiman de los primeros, lo que es cognitivamente imposible, incluso para los investigadores, por ejemplo:

A: Investigador afuerino; B: Atacameño. De un modo esquemático tenemos por lo menos cuatro posibilidades de percepciones identitarias:

1) Lo que A percibe de A, es decir su propia identidad.

2) Lo que A percibe de $B$, es decir la percepción que A tiene de la identidad de $\mathrm{B}$, o mejor dicho de la "alteridad" de B en relación a la identidad de $\mathrm{A}$.

3) Lo que B percibe de A, es decir la alteridad de $A$, en relación a la identidad de $B$.

4) Lo que B percibe de B, su identidad, la definición interna de su identidad.

El problema que habitualmente sucede, es que irreflexivamente se toman como equivalente las opciones 2 y 4 , en términos que el investigador es capaz de adentrarse tan profundamente en la identidad del indígena, hasta el grado que perciban lo mismo, lo que no es posible, por mayores y más altruistas que sean los sentimientos y aspiraciones del investigador. Es una aberración considerar o confundir como iguales las percepciones de identidad con las percepciones de alteridad. En todo caso, por supuesto, hay que tener presente el profundo sustrato de hegemonía ideológica que sobre los indígenas (en este caso sobre los atacameños), tiene y significa una postura de este tipo.

Afirmamos entonces que la identidad no es lo 
mismo que la alteridad, aunque se refieran al mismo espacio de etnicidad; en este punto es menester profundizar nuestra visualización crítica a lo que en su momento llamamos esencialismo culturalista. Si alguien externo a la cultura y a la identidad atacameña, sea investigador o no, se aproxima, entra en contacto con la alteridad de lo atacameño, desde el principio hasta el final, lo que ve son manifestaciones, elementos culturales, que pueden ir desde los rituales, o el parentesco hasta los procesos de trabajo y la cultura material, entre otros. Ya sea que se enfile en un camino positivista de estadística de encuestas, o desde el camino interpretativo de entrevistas en profundidad. En ambos casos se encuentra con elementos culturales, de muy diferente índole -- sería absurdo negarlo -- pero, finalmente se enfrenta a una externalidad cultural. En tal sentido, considero fecundo rescatar a dos autores emblemáticos de estas posiciones epistemológicas tan distanciadas, pero que finalmente tienen que abordar desde sus respectivas perspectivas, los rasgos culturales de la alteridad, nos referimos a George Peter Murdock y a Clifford Geertz.

Con su trabajo de acopio clasificatorio de datos y sistematización estadística, en el Human Relations Area Files (H.R.A.F.), de la Universidad de Yale desde 1936, Murdock (1994 [1950]), lleva hasta límites insospechados un aspecto que es intrínseco de la historia de la antropología, el análisis detallado en torno a la comparación intercultural como una herramienta heurística de primer orden, se jerarquizan y cuantifican rasgos culturales, con la voluntad de reflexionar sobre correlaciones $y / 0$ dispersiones sociales y culturales, que no se podrían discernir en un primer momento. Este objetivo, es por decir lo menos, loable, no en vano este esfuerzo se sigue realizando por los discípulos de Murdock.

Por otra parte, nos referiremos a uno de los trabajos más conspicuos de Geertz, la llamada "descripción densa" (Geertz, 1992 [1973]:19-40), precursora del movimiento postmoderno en antropología, en donde afirma que el investigador realiza "interpretaciones de segundo orden", ya que frente a la solicitud del propio investigador, el o los informantes, realizan una primera interpretación de su cultura o de identidad étnica, el investigador se ve obligado a hacer su interpretación sobre la interpretación previa del informante, es decir una interpretación de la interpretación. Geertz, sagaz al fin, jamás ha pretendido que sus interpretaciones culturales sean más válidas o verdaderas que las del actor social que vivencia plena y directamente su identidad.

Nos enfrentamos entonces a la paradoja que dos marcos teóricos y metodológicos considerados como opuestos, tienen una convergencia ontológica, ambas son aproximaciones externas a la identidad del otro, o mejor dicho, son abordajes científicos y externos de la alteridad. Aunque hay que ser enfáticos, en lo absoluto esto significa que ambas aproximaciones sean similares o analogizables, son puntos de convergencia, no homologaciones teórico-metodológicas.

La comprensión de la externalidad propia del estudio de la alteridad, o si se quiere de la identidad del otro, tiene particular importancia para el estudio de la identidad en general, y de la identidad étnica en particular, como en el caso de los atacameños, que es el que congrega estas reflexiones, así reiteramos, no es lo mismo la identidad que un grupo ha generado para sí mismo que la imagen que otros han construido de ellos. En tal sentido, como es evidente, es prácticamente imposible que ambas imágenes identitarias coincidan completamente, lo que genera un interjuego, un espacio de negociación entre la identidad y la alteridad de los grupos socio-culturales, a este espacio, en el caso de la identidad étnica, le llamaremos "etnicidad".

Las relaciones étnicas son sociales, pero los significados de las mismas son culturales, en tal sentido, la etnicidad es un espacio sociocultural, y como tal sujeto a significaciones multidimensionales y a configuraciones sintéticas de las mismas significaciones, por lo que es habitual que dentro del espacio de la etnicidad se manifiesten fenómenos que no son exclusivamente étnicos, es decir, junto con lo étnico aparecen identidades, afinidades y conflictos de la más diversa índole, todos los cuales tienen una profunda carga emocional, pero también una racionalidad instrumental, de allí la importancia de rescatar los contextos donde se expresa la etnicidad, la cual puede aparecer asociada a los conflictos de clases sociales, los manejos territoriales, la competencia sobre 
recursos, los desarrollos económicos, las segregaciones en torno a fenotipos raciales, las identidades religiosas, los procesos políticos, las desigualdades de género, los desplazamientos linguiísticos, entre muchos otros.

Tenemos entonces, que este campo cultural de lo étnico se relaciona con otros aspectos de las negociaciones, de los conflictos y de las conciliaciones de los conglomerados sociales humanos, el caso más recurrente de convergencia dentro de la literatura antropológica latinoamericana de corte marxista, hasta fines de la década de los ochenta, es la contigüidad entre etnia sojuzgada y clase social explotada (Burguete Cal y Mayor, 1984), aunque considero que es un error pensar que ontológicamente son lo mismo. ¿Por qué convergen entonces?, el debate para responder esta pregunta está lejos de dirimirse, siguiendo a Adams (1995a y 1995d), el sustento unificador estaría dado por la sobrevivencia social, entonces etnicidad, clases sociales, territorialidad, y otros, son "vehículos de sobrevivencia" (Adams, 1995d: 157-182), que busca mantener a tales o cuales grupos humanos vigentes, y la convergencia de estos vehículos es porque la complejidad y magnitud del desafío es tan grande que un vehículo por si solo no es suficiente para este gran cometido.

Como el sentido étnico, es en su sustancia eminentemente cultural, la transmisión cultural fundamentalmente en el ámbito familiar y comunitario, lo que se conoce como enculturación, es también la transmisión del sentido étnico de la identidad personal y social, y de los parámetros de identificación étnica de la alteridad de lo otros grupos y personas. Es importante señalar que como en todo procesos de enculturación, la transmisión del sentido étnico no viene con un certificado de garantía, no es automática la solidaridad y la empatía emocional de las personas dentro de su etnia, puede salir al revés, es decir, que surjan elementos sociales cuestionadores de esta solidaridad étnica y que además al entrar en espacio de negociación de la etnicidad juegan para el otro equipo, en México a este fenómeno le denominan Malinchismo.

Por otra parte, en la transmisión de los contenidos culturales, en este caso étnico-culturales, puede que estos no sean los mejores o incluso pueden ser los peores (aunque habría que determinar para quien es lo mejor y para quien lo peor), es decir no toda la enculturación familiar y/o comunitaria es sublime o enriquecedora para sus miembros, o sea, existen muchos problemas que se dan en el ámbito doméstico y comunitario, de allí que exista la violencia intrafamiliar, las crisis generacionales o las segregaciones comunitarias, entre otros; no porque se enmarque dentro de lo étnico-cultural va quedar inmediatamente libre de este tipo de problemas, reitero, no todo lo que se transmite en la enculturación es sublime, porque estamos hablando de personas, de seres humanos y como tales imperfectos, con virtudes y defectos, como todo el mundo, en todas las culturas, de lo contrario, estaríamos frente a un estructural-funcionalismo extremo, aún mayor que el de Parsons o el de Laszarfeld, en donde todo lo adjetivado étnicamente funcionaría impecablemente, lo que considero simplemente como insostenible.

La etnicidad, como reseñó en su momento Eriksen (1993: 37), es un concepto tardío, acuñado en el ámbito de la sociología por Riesman en 1953, para dar cuenta de algo evidente, esto es la correspondencia recíproca entre grupos y/o personas diferentes entre sí, o dicho de otro modo, el grupo A antes mencionado existe como $\mathrm{A}$, porque existen otros grupos que no son A, pueden ser B, C, D, etcétera. Por supuesto, Fredrik Barth, en su artículo de 1969 (1976[1969]), sobre las fronteras étnicas, y en general a lo largo de todo su trabajo de décadas, especialmente entre etnias musulmanas no-árabes (especialmente en Irán y Pakistán), fué quien más claramente explicitó esta necesidad de pensar las delimitaciones y las conexiones interétnicas para entender la cambiante dinámica de la etnicidad en su acepción más amplia. Se ha comentado que esta posición teórica ha sido tomada acríticamente en América Latina, no obstante que en el mundo ha generado una incesante polémica, con ríos de tinta para escribir argumentos a favor y en contra de la misma, incluso se han llegado a plantear conceptos e ideas atribuidas a Barth, que él no reconoce como propias.

A raíz de la vigencia del debate y de las confusiones autorales que han girado en torno a ella, tuvo que ser el propio Barth en 1994, veinticinco años después quien escribiera un nuevo artículo retrospectivo y con un poco de autocrítica, con el ánimo de hacer aclaraciones teóricas y del entorno 
que rodeó a las reflexiones de su muy importante artículo de 1969. Aunque también hace nuevos aportes, los que están acordes con los avances en la discusión sobre la cuestión étnica en los últimos años, en este punto, considero importante resaltar el énfasis que él otorga a la porosidad de estas mencionadas fronteras étnicas y a la trascendental importancia que en el mundo contemporáneo tiene la interrelación cultural entre lo étnico y las diversas facetas del poder estatal (Barth, 1994: 19-31). También en esta línea interaccionista, heredera de los trabajos de Erving Goffman, por cierto, Barth apunta analíticamente a tres espacios interactivos de desenvolvimiento de la etnicidad, los cuales son: a) el espacio personal, b) el espacio generado por los movimientos sociales, y c) aquel que gira en torno a la aglutinación ideológica de la actividad política en proceso de centralización del poder.

El debate contemporáneo sobre la cuestión étnica es enorme, por lo que sólo hemos mostrado pinceladas, entre otros por su impactante vigencia producto de los cada vez más extendidos conflictos étnicos, en los Balcanes, Africa, Asia, etcétera. Pero nuestro interés es hacer aportes al estado del arte en Atacama y lo primero que llama la atención, es que el desarrollo de las fuerzas políticas y sociales, más evidentemente a partir de la promulgación de la Ley Indígena de 1993, han estado a la vanguardia del debate, aunque de un modo un tanto caótico. Las reflexiones y los análisis teórico-metodológicos de los investigadores se han retrasado, por razones de la más diversa índole, aunque dentro del conjunto de ellas destaca la debilidad institucional para el respaldo de las ciencias sociales, durante las últimas décadas, lo que lentamente se ha ido revirtiendo, junto con una apertura de posibilidades de financiamiento, aunque todavía con montos reducidos.

Circunscribiendo nuestra atención a los aspectos académicos del debate antropológico, debemos decir que prevaleció por demasiado tiempo una extraña mezcla de falta de etnografías especializadas, que apuntaran sistemáticamente a abordar aspectos estructurales del desarrollo social y cultural de los atacameños contemporáneos, tales como el parentesco, las relaciones de género, la inserción en los mercados laborales regionales, las dinámicas de los espacios domésticos y su vincu- lación con la estructura de la política interna de las comunidades y las relaciones de poder entre las comunidades entre sí, la migración urbana, etcétera. Lo que se ha hecho, son etnografías, la mayoría tesis de grado con recursos muy precarios, que han abordado temáticas amplias en torno a alguna comunidad en particular. Uno de los resultados, ha sido paradójicamente, una visión que trata de descubrir reductos culturales, esencias de lo indígena, pero que se han convertido en una acumulación de rasgos culturales, los cuales son inevitables como hemos visto, pero su importancia radica en su puesta en juego en la acción social, y no en la acumulación arbitraria de todo lo que suene profundamente indígena.

En otra palabras, este intento de primordialismo ha redundado en un intento fallido de hipóstasis sociocultural. Aquí me remito a Durkheim, un ejemplo clásico de hipóstasis en nuestras disciplinas. El sustento profundo de la vida social estaría dado para Durkheim por la unidad última e inconciente de la humanidad, tal como lo abordó en su estudio de las clasificaciones primitivas de 1902, junto con Mauss (Durkheim, 1996 [1902]), así como en su libro sobre las formas elementales de la vida religiosa de 1913. En tal sentido, las representaciones colectivas, como es el caso de las clasificaciones culturales (hoy las Ilamaríamos etnocategorías clasificatorias), son producto de la síntesis de la experiencia concreta y la unidad inconciente general. Como es de esperar esta proposición de Durkheim ha generado un debate que aún no se resuelve.

En Atacama no se ha pretendido tanto en el plano de las hipóstasis, más bien se ha buscado en la acumulación de los rasgos de alteridad, una suerte de sustento último de la esencia de lo atacameño, un sustento que estaría resistiendo los embates de la modernidad gracias a alguna razón desconocida, embates tales como el turismo, la minería, la televisión, entre otros. Como ha sido una razón hipostática desconocida y no encontrada, se ha caído en una suerte de criptología culturalista, donde no encaja la modernidad, pero que se la acepta, por su innegable presencia en las comunidades atacameñas. Esta búsqueda críptica, es decir sin una mayor claridad sobre lo que se busca, ha redundado en algunos casos, en trivialidades en las reflexiones, y en la pérdida de los escasos 
recursos de varios proyectos aplicados, dado que ha existido cierta oscuridad tanto en la definición del objeto de estudio, como también en el debate metodológico que gira en torno a tan brumoso objetivo.

No pretendo perjudicar el trabajo de algún investigador, por lo que no he hecho referencias específicas, pues estaría fuera de foco, en relación a los reales problemas de la investigación en esta región, y por cierto, no todos los trabajos caen en esta descripción, es más ya existen etnografías notables, por lo que sugiero que releamos a Barth y a los interaccionistas (pueden existir otras sugerencias, por supuesto), veamos límites y contactos étnicos concretos, evoluciones sociales específicas, en fin temas abordables y no esencias crípticas de lo étnico, como hace el excelente libro de etnohistoria de José Luis Martínez sobre los Atacamas del siglo XVII (Martínez, 1998), siguiendo la mejor tradición de los trabajos de Jorge Hidalgo, que tanto han alimentado los pensamiento sobre el fenómeno atacameño en la historia. Ojalá sucediera algo así en la antropología, un impulso que permitiera pasar a un nivel superior de debate académico, que pudiera repercutir con mayor fortaleza en el desarrollo de los atacameños contemporáneos y futuros.

Finalmente es necesario tener presente que el cambio, la adaptación y las proposiciones culturales innovadoras frente a los desafíos, son una constante de todos los tiempos y lugares. En tal sentido, el concepto de "comunidad indígena tradicional", como el reducto de la pureza y resistencia étnica, desde tiempos precolombinos, es por lo menos algo discutible. En dichos términos, es menester recordar un trabajo clásico de la antropología del recientemente fallecido Eric Wolf (1981 [1957]), sobre las comunidades corporativas cerradas, en donde él comienza un serio cuestionamiento sobre la irreductibilidad de las comunidades, debate que es continuado por Fernando Fuenzalida (1976), para los Andes Centrales.

La reflexión que cabe sobre estos análisis, radica en por lo menos dos puntos, el primero es que la hibridación cultural y política viene desde el momento mismo de la conquista europea del siglo XVI, y segundo, antes de ese etnocidio histórico los indígenas, en este caso atacameños y etnias vecinas, ocupaban todos los nichos ecológicos posibles en estas tierras del desierto de Atacama, por lo que su aproximación a territorios extra comunitarios es simplemente un modo de revertir y recuperar el protagonismo perdido por la sujeción a poderes centrales faltos de la sensibilidad suficiente como para percatarse de estos procesos sociales. Incluso el turismo masivo y la globalización económica y massmediática, con toda su carga aculturadora, por una parte homogenizan ciertos rasgos culturales de lo que llamamos identificación externa, pero por otra parte aumentan los puntos de encuentro, las fricciones, o en los términos de Barth, contribuyen a la creación, recreación y consolidación de las fronteras étnicas. Ahora, el estímulo de la alteridad ya no sólo es local y/o nacional, sino que ahora es también global, por lo mismo, considero que el proceso de la etnicidad emergente está cada vez más presente en Atacama, e invito a que desde ya nos dediquemos a estudiarla. 


\section{BIBLIOGRAFÍA}

ABERCROMBIE, T., To be indian, to be bolivian. En Nation1991 States and indians in Latin America (Greg Urban and Joel Sherzer, eds.). Austin. The University of Texas Press.

1992 Articulación doble y etnogénesis. En Reproducción y transformación de la sociedades andinas, siglos XVI-XX. Tomo I. (Segundo Moreno y Frank Salomon, comps.). Quito. Ediciones ABYA-YALA/MLAL.

ADAMS, $R$. Dos características básicas de la etnici1995 dad (trad. Guadalupe González y José Hernández). En Etnías en evolución social. Estudios de Guatemala y Centroamérica. México D.F. Universidad Autónoma Metropolitana-Iztapalapa.

1995b "Surgimiento y supervivencia étnicos en centroamérica". (trad. Guadalupe González y José Hernández). En Etnías en evolución social. Estudios de Guatemala y Centroamérica. México D.F. Universidad Autónoma MetropolitanaIztapalapa.

1995c "La dinámica de la diversidad social: Notas desde Nicaragua para una sociología de la supervivencia". (trad. Guadalupe González y José Hernández). En Etnías en evolución social. Estudios de Guatemala y Centroamérica. México D.F. Universidad Autónoma Metropolitana-Iztapalapa.

BARTH, F. "Introducción" En Los grupos étnicos 1976 [1969] y sus fronteras. la organización social de las diferencias culturales (Fredrik Barth, Ed.). México D.F. Fondo de Cultura Económica.(trad. Sergio Lugo). "Introduction". Ethnic groups and boundaries. The social organization of culture difference. Oslo. Universitetsforlaget.

1994 "Enduring and emerging issues in the analysis of ethnicity". En The Anthropology of ethnicity. Beyond 'ethnic groups and boundaries' (Hans Vermeulen and Cora Govers, eds.). Amsterdam. Het Spinhuis.

BURGUETE CAL y MAYOR, A., "¿Quiénes son los Ami1984 gos del Indio'?". En Revista de Antropología Americana No9:13-36. México D.F. Instituto Panamericano de Geografía e Historia.
CARRASCO, S. Historia de las relaciones chileno-bo1990 livianas. Santiago. Editorial Universitaria.

CASTRO, V. y J. L. MARTÍNEZ. "Poblaciones indígenas 1996 de Atacama". En Culturas de Chile. Etnografía. Sociedades indígenas contemporáneas y su ideología. (Jorge Hidalgo, Virgilio Schiappacasse, Hans Niemeyer, Carlos Aldunate y Pedro Mege, eds.). Santiago de Chile. Editorial Andrés Bello/Fundación Andes/Sociedad chilena de Arqueología.

DURKHEIM,É. y M. MAUSS. "Sobre algunas formas pri1996 [1902] mitivas de clasificación" En Clasificaciones primitivas y otros ensayos de antropología positiva (Émile Durkheim). Barcelona. Editorial Ariel (Manuel Delgado, trad.).

ERIKSEN, T. Ethnicity and Nationalism. Anthropo1993 logical perspectives. London. Pluto Press.

FUENZALIDA, F. "La estructura de la comunidad indíge1976 na tradicional." En Hacienda, comunidad y campesinado en el Perú. (José Matos Mar, comp.). Lima. Instituto de Estudios Peruanos.

GEERTZ, C. La interpretación de las culturas. Bar1992 [1973] celona Editorial Gedisa. The interpretation of cultures. New York. Basic Books Inc.

MARTÍNEZ, J. Autoridades en los Andes, los atribu1995 tos del Señor. Lima. Fondo Editorial de la Pontificia Universidad Católica del Perú.

1998 Pueblos del Chañar y el Algarrobo. Los Atacamas en el siglo XVII. Santiago de Chile. Ediciones de la Dirección de Bibliotecas, Archivos y Museos (DIBAM-Chile)-Centro de investigaciones Barros Arana / Facultad de Filosofía y Humanidades de la Universidad de Chile

MURDOCK, G. Guía para la clasificación de los da1994 [1950] tos culturales. México D.F. Universidad Autónoma Metropolitana-Iztapalapa. Outline of cultural materials. New Haven. Human Relations Area Files (H.R.A.F.), University of Yale.

NÚÑEZ, L. Cultura y conflicto en los oasis de San 1992 Pedro de Atacama. Santiago. Editorial Universitaria. 
NÚÑEZ, L.; A. LLAGOSTERA, H. A.LONSO et al. Progra1988 ma de etnodesarrollo de San Pedro de Atacama. Antofagasta. Universidad del Norte, Ms.

REDFIELD, R. The little community, Chicago. The 1973 [1953] University of Chicago Press. Uppsala. Gottesman lectures vol V. Uppsala University.

REDFIELD, R., R. LINTON y M. HERSKOVITS "Memorán1986 [1936] dum para el estudio de la aculturación". En Arinsana $\mathrm{N}^{\circ} 3: 7-15$. Cusco.

RIVERA, F., 1997
El caso de la minería industrial del cobre en el norte de Chile: Construcción de identidad étnica, metáfora cultural y relaciones laborales (Ms) México D.F. Universidad Autónoma Metropolitana-Iztapalapa. Departamento de
Sociología. Area de Sociología del Trabajo.

1998a "Procesos de articulaciones socioidentitarias y reformulaciones étnicas en Atacama". En Estudios Atacameños N 13:61-73. San Pedro de Atacama.

ROOSENS, E. Creating Ethnicity. The process of 1989 ethnogenesis. Newbury Park. Sage Publications.

WOLF, E. 1981

"Comunidades corporativas cerradas de campesinos en Mesoamérica y Java central". En Antropología económica. Estudios etnográficos (Josep Llobera, comp.). Barcelona. Editorial Anagrama. [1957] Southwestern Journal of Anthropology vol 13 N 1:167-182. 